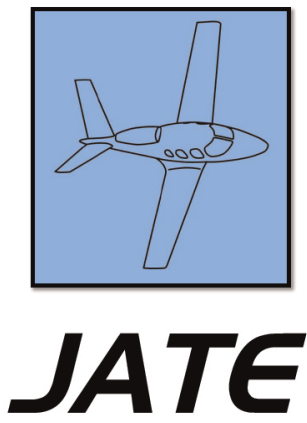

Journal of Aviation Technology and Engineering 2:1 (2012) 130-135

DOI: $10.5703 / 1288284314865$

\title{
The Cooperative Fuels Research Engine: Applications for Education and Research
}

\author{
Christopher Brock and David L. Stanley \\ Purdue University
}

\begin{abstract}
Lead is currently banned from most gasoline because it is harmful to humans. While aviation gasoline still contains lead, this may change in the near future due to increased regulation in the interest of public safety. This has created a research opportunity to verify that new unleaded aviation fuels are compatible with equipment currently in use. The Cooperative Fuels Research (CFR) engine is designed for the controlled experimental testing of fuels involving spark-ignition, piston engines. The CFR engine enables scientists and engineers to ascertain engine performance as it relates to fuel, including heat content, detonation characteristics, and ultimately the fuel octane number. An initiative is underway in the Aviation Technology Department at Purdue University to update and make operational a CFR engine. With this test engine fully functional, scientists, engineers and students will have another cutting-edge tool for both education and research in the arena of new aviation fuels.
\end{abstract}

Keywords: CFR engine, lead, alternative fuels

\section{Introduction}

Fuels are the backbone of modern society, and are particularly critical for transportation. Most of today's transportation fuels are petroleum-based, which are unstable in price and under close scrutiny due to concern over combustion emissions. This, coupled with the fact that world population is rapidly increasing and the use of petroleum products is, therefore, growing at an equally rapid pace, is placing increased pressure on fuel supplies. Additionally, the aviation industry is handicapped by the fact that gasoline contains tetraethyl lead (TEL), typically referred to simply as lead. TEL is added to

\section{About the Authors}

Christopher Brock is a Graduate Research Assistant at Purdue University in the department of Aviation Technology. He currently holds an Airframe and Powerplant mechanics certificate as well as a Bachelor's degree in Aeronautical Engineering Technology (AET) from Purdue University.

David L. Stanley is an Associate Professor of Aviation Technology at Purdue University, West Lafayette. He currently holds an Airframe and Powerplant mechanics certificate. He currently teaches powerplant system courses within the department of Aviation Technology. His research interests include alternative fuels. 
fuels to boost the octane content of the fuel, enabling engines to produce more power with improved performance. TEL, however, is known to be toxic to humans and has already been phased out of all other types of transportation fuels. New regulations are expected to mandate the elimination of lead from aviation gasoline as well, but before this can happen, new fuels that do not contain harmful substances but that produce similar performance characteristics must be developed.

Although lead emissions have not yet been deemed hazardous to human health, elemental lead is known to be particularly harmful to children. "Elevated levels of lead can damage organs and the brain and nervous system, and affect the heart and blood. Adverse health effects range from behavior disorders and anemia to mental retardation and permanent nerve damage" (United States Environmental Protection Agency, 2012, para. 6). In the mid-1970s, the Environmental Protection Agency (EPA) began to phase out lead and by 1996, leaded gasoline was banned as a result of the Clean Air Act (United States Environmental Protection Agency, 2012). "The Clean Air Act required the EPA to issue a series of rules to reduce pollution from vehicle exhaust, refueling emissions and evaporating gasoline. As a result, emissions from a new car purchased today are well over 90 percent cleaner than from a new vehicle purchased in 1970" (United States Environmental Protection Agency, 2012, para. 6).

Aviation gasoline and off-road vehicle fuels were exempted from the previously stated law because the Clean Air Act did not specifically mention them. Recently, due to the fact that aviation accounts for approximately $45 \%$ of all airborne lead emissions, increasing attention has been focused on leaded aviation gasoline (also known as avgas). In early 2011, the California Center for Environmental Health $(\mathrm{CEH})$ demanded that all California distributors of avgas immediately cease the sale of avgas and pay fines and legal fees of up to $\$ 1.3$ billion per company (National Air Transportation Association, 2011). The request was later modified to include two choices - pay the fines and either cease and desist, or warn anyone living in/passing through the surrounding area about the dangers posed by lead.

In a hearing last week at the U.S. District Court, Eastern District of California in Fresno, California, federal judge Anthony Ishii requested additional briefings be filed before ruling on a motion to dismiss the case brought by ... avgas distributors ... in response to the CEH's threat of a suit over the sale of leaded gasoline (National Air Transportation Association, 2011, para. 1).

This is just one example of the legal complications surrounding avgas. Clearly, the issue is volatile. The outcome of this case and others like it could affect the general aviation community by acting as a catalyst to accelerate the removal of TEL from all avgas.
With the supply and pricing issues that plague petroleum-based fuels coupled with the need to remove TEL from avgas, new unleaded fuels will need to be developed for aviation. As this research moves forward, one of two things must occur: either new fuels compatible with the previous fuels and equipment must be designed, or the fuels industry must "force" manufacturers to adapt equipment to the new fuels. The latter approach may create a compatibility issue, as new fuels may not function properly with existing equipment, a situation generally considered unacceptable. The prevailing research philosophy has been that new fuels must "drop-in", functioning in every way at least as well as those they replace.

In order to resolve these issues, new fuels must be developed that are not only compatible with today's equipment, but also unleaded. In order to verify that these fuels fulfill all requirements, comprehensive testing will be required. Additionally, from an educational perspective, aviation students can be taught how to design, set up, and perform the experiments required. Today, students and faculty members are working to restore and modernize a Cooperative Fuel Research (CFR) engine housed at Purdue University. Once this effort is completed, the test engine will be used to conduct research on fuel performance and will serve as a learning laboratory for students.

\section{Background}

The CFR engine is a test engine developed by Waukesha Motor Company specifically to test fuels used with sparkignition reciprocating engines. This specific unit has an adjustable compression ratio, which can vary from $4: 1$ to 10:1, adjustable ignition timing, and the capability to test three fuels in sequence. The engine has a total displacement of 37.3 cubic inches, and weighs approximately 650 pounds (Coodinating Fuel Research Committee, 1945).

A discussion of gasoline properties will provide a background for the application of the CFR test engine. Aviation gasoline has specific characteristics, including high heat value and an evaporation rate appropriate for the conditions under which aircraft operate.

Gasoline is rated for engine fuel purposes according to its anti-knock value; this value is expressed in terms of an octane number. Chemically, gasolines are classified as mixtures of hydrocarbons ... Lead, in the form of tetraethyl-lead (TEL), is used in relatively small quantities in aviation gasoline to improve anti-knock qualities (Kroes \& Wild, 1995, p. 110).

For aviation engines, fuels with high resistance to detonation, or knock, as it is commonly referred to, are critical for high horsepower output.

Engine knock [is] a phenomenon where the engine would make a loud pinging or knocking sound as it ran at high power. It was found that when engines displayed this knocking sound, internal damage and failure of parts in the combustion 
chamber were often found. In some cases, catastrophic engine failures would occur (Ziulkowski, 2011, p. 23).

According to Hamilton and Cowart (2008), engine knock has been a concern since the invention of the internal combustion engine. "Engine knock continues to limit spark-ignition gasoline engine compression ratios and thus engine efficiency and torque" (Hamilton \& Cowart, 2008, p. 97). As a result of the limitation brought on by knock, engineers and scientists searched for methods that help mitigate this phenomenon.

In one of the most significant discoveries involving gasoline performance, the anti-knock properties of tetraethyl lead (TEL) were discovered in 1921. Unfortunately, when TEL was added to the fuel, the resultant lead oxide quickly plated out on engine surfaces, precluding its use. Not until the advent of lead scavenger additives did the use of TEL become practical (Coordinating Research Council, 2004, p. 1-38).

The Cooperative Fuel Research committee (CFR) was also created in 1921.

The CFR was an early predecessor to what we now recognize as ASTM International. This group was comprised of well-educated petroleum engineers from countries in Europe and the United States. Even though these advances were occurring and engineers were beginning to study gasoline, it would still take some more time to develop before this knowledge and technology was applied to aviation (Ziulkowski, 2011, p. 24).

\section{Determining Octane Value}

The anti-knock number, more commonly known as the octane number, is of interest to scientists and engineers because it is an indicator of fuel performance. It is therefore important to understand the process by which a fuel octane number is found. "The matching method of measuring knock rating is invariably used with the bouncing pin. In this method, standard fuels are required, one of the higher and the other of lower knocking properties than those of the gasoline with which they are to be compared" (Royal Dutch-Shell Group, 1938, p. 242). "About the year 1927, Dr. Edgar of the Ethyl Gasoline Corporation suggested as a common standard for all laboratories, two pure chemical substances which can be used as engine fuels" (Royal Dutch-Shell Group, 1938, p. 243). Edgar chose two pure chemicals, normal heptane, the lower anti-knock chemical, and iso-octane, the higher anti-knock chemical. According to the Royal Dutch-Shell Group, using two pure chemical compounds as a standard for determining octane is advantageous in that the chemical properties of these compounds are essentially fixed and do not vary. Generally speaking, aviation fuels are a combination of multiple hydrocarbons, making their use for standard purposes difficult.

As previously mentioned, the method for determining the octane number and measuring knock is the bouncing pin method. An adjustable bouncing pin mechanism is described as follows:

A thin metal diaphragm is fixed over a hole in the cylinder head, similar to the socket into which the sparking

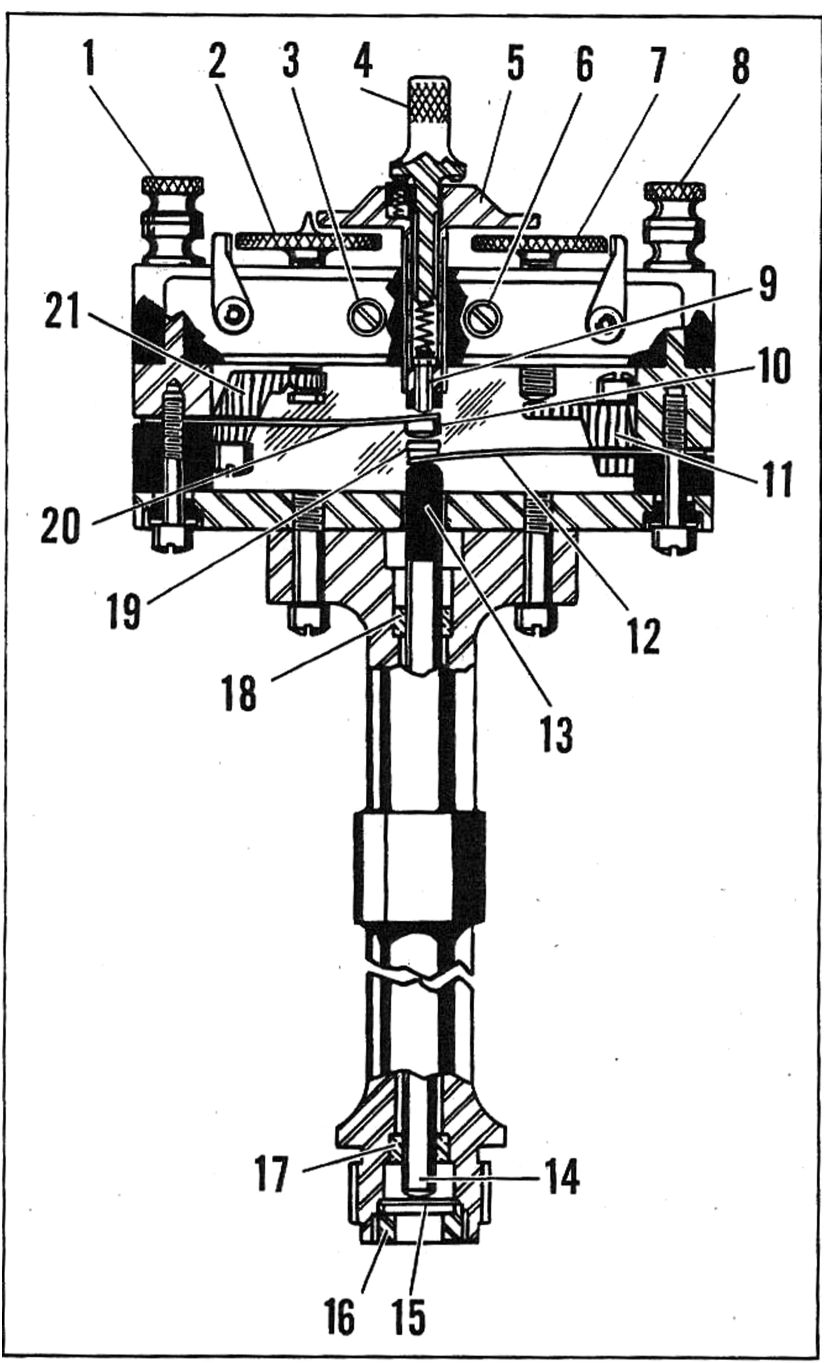

FIG. 26-STANDARD ADJUSTABLE BOUNCING PIN

$$
\begin{aligned}
& \text { 1-Upper Contact Terminal } \\
& \text { 2-Upper Contact Adjusting Screw } \\
& \text { 3-Adjustment Locking Screw } \\
& \text { 4-Bumper Spring Adjusting Screw } \\
& \text { 5-Center Adjusting Screw } \\
& \text { 6-Adjustment Locking Screw } \\
& \text { 7-Lower Contact Adjusting Screw } \\
& \text { 8-Lower Contact Terminal } \\
& \text { 9-Bumper Pin } \\
& \text { 10-Upper Contact } \\
& \text { 11-Lower Contact Spring Anchor Block } \\
& \text { 12-Lower Contact Spring } \\
& \text { 13-Fibre Tip of Bouncing Pin } \\
& \text { 14-Bouncing Pin, Stellite Tipped } \\
& \text { 15-Steel Diaphragm } \\
& \text { 16-Hollow Lock Nut Holding Diaphragm } \\
& \text { 17-Lower Guide Bushing for Pin } \\
& \text { 18-Upper Guide Bushing for Pin } \\
& \text { 19-Lower Contact } \\
& \text { 20-Upper Contact Spring } \\
& \text { 21-Upper Contact Spring Anchor Block }
\end{aligned}
$$

Figure 1. A cross-sectional view of a standard adjustable bouncing pin. (Courtesy of Cooperative Research Council; reprinted with permission.) 


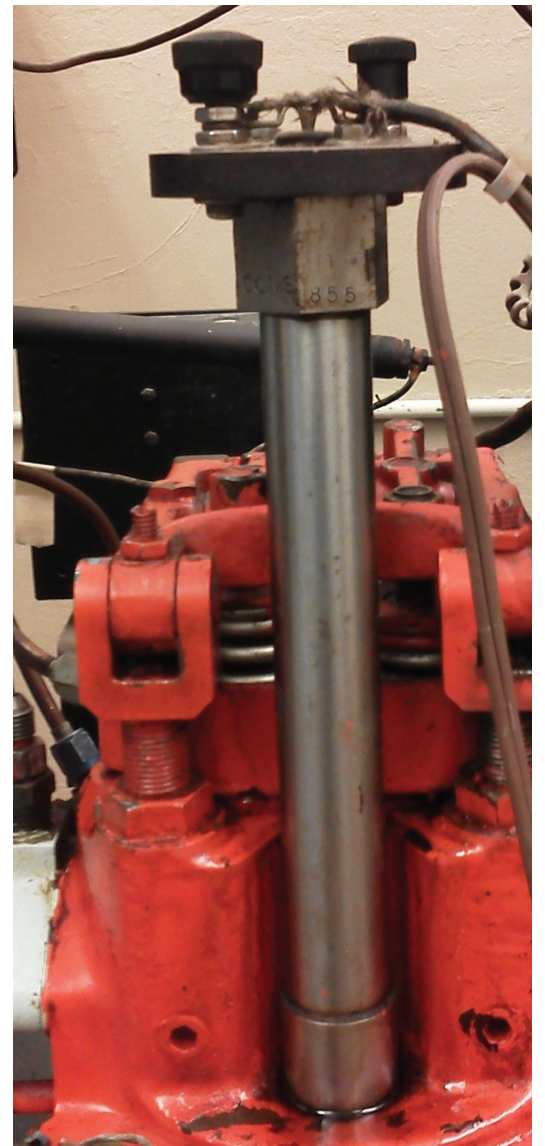

Figure 2. Example of an adjustable bouncing pin. (Picture taken by the author; printed with permission.)

plug is screwed. Standing on the diaphragm is a light metal rod, on the top of which presses a leaf spring. Immediately above this spring and separated from it by a few thousandths of an inch, is a second leaf spring. These springs form part of an electrical circuit, the bouncing pin circuit. The circuit is open and no current flows while the engine is at rest or running without detonation" (Royal Dutch-Shell Group, 1938, p. 241).

Knock testing is a complicated matter, as the intensity of the knock depends on the conditions under which the fuel, which itself may have varying anti-knock characteristics, is being used. "The method of test first employed with the CFR engine was that later known as the "research method" (Royal Dutch-Shell Group, 1938, p. 245). In the 1930s, scientists and engineers compiled data about typical fuels used at that time and then compared them to a set of reference fuels with respect to detonation characteristics in car engines.

In this way an average octane number was obtained for each fuel based on its performance in a number of multicylinder engines A test method was then worked out in the CFR engine to give the same octane number to each fuel as the average of the car results. This method of test in the CFR engine is known as the 'motor method' and has

\begin{tabular}{|l|cr|c|}
\hline \multicolumn{1}{|c|}{ Fuel } & \multicolumn{2}{|c|}{$\begin{array}{c}\text { Knockmeter } \\
\text { Readings }\end{array}$} & $\begin{array}{c}\text { Average } \\
\text { Readings }\end{array}$ \\
\hline 80 Octane Reference Fuel Blend & 60 & 58 & $\mathbf{5 9}$ \\
Test Sample & $\vdots$ & $\mathbf{5 6}$ & $\mathbf{5 6}$ \\
82 Octane Reference Fuel Blend & 46 & 48 & $\mathbf{5 7}$ \\
\hline
\end{tabular}

Figure 3. An example of the order in which to test the given fuels. Note, that the higher octane fuel has a lower knockmeter reading. (Courtesy of Cooperative Research Council; reprinted with permission.)

remained the standard test procedure (Royal Dutch-Shell Group, 1938, p. 245).

\section{CFR Engine Applications}

This engine allows the operator to adjust a variety of engine parameters. By controlling the test parameters of ignition timing, compression ratio, and fuel choice, the operator is able to determine the octane rating of a fuel through a process of interpolation. The test process involves operation with two reference fuels-normal heptane (lower octane) and iso-octane (higher octane)and recording of the knockmeter readings with both (Coodinating Fuel Research Committee, 1945). "The sequence used in recording them is: Low reference fuel, test sample, high reference fuel, test sample, low reference fuel, test sample, high reference fuel" (Coodinating Fuel Research Committee, 1945, p. 41). "The knockmeter readings for each fuel should be averaged as shown in the example and the octane number of the test sample interpolated from those of the two reference fuel blends" (Coodinating Fuel Research Committee, 1945, p. 42). The example is found in Figure 3. Note, that the knockmeter readings will likely be higher for the lower octane fuel, as this indicates higher knock intensity. Conversely, the higher octane fuel will have a lower knockmeter reading due to lower knock intensity if the operator were to mix an alternative fuel and a fuel currently in use, and then find the octane rating of the blended fuel; this engine could be used to determine the octane rating. This engine also allows for the alteration of the fuel/air mixture, which also has a direct impact on the occurrence of detonation. This is important in fuels research due to the fact that "maximum knock intensity is generally obtained at the fuel-air ratio approximating that for complete combustion, the knock intensity decreasing as the fuel-air ratio is either decreased or increased" (Coodinating Fuel Research Committee, 1945, p. 40).

This engine also has significant educational potential, as it will provide a framework for students to learn experimental project design and set up, and development of test protocol for operations involving fuels and reciprocating engines.

CFR engines have been used in many studies over the years, advancing the boundaries of our collective knowledge: 
Compression ignition by air injection (CIBAI) has been successfully achieved in a modified single cylinder, fourstroke, spark ignition cooperative fuel research (CFR) engine ... [which] has the potential to replace traditional spark ignition and high pressure fuel injection controlled ignition (Echavarria, Loth, \& Morris, 2006, Abstract).

If this new combustion concept is successful, it would allow internal combustion engines to achieve greater efficiency and increase fuel economy.

In yet another study, "a co-operative fuels research (CFR) gasoline engine is used to evaluate torque and measure in-cylinder and exhaust $\mathrm{CO}, \mathrm{CO}_{2}$, and unburned hydrocarbons under various fuelling and spark conditions during cranking and startup phases" (Cowart \& Hamilton, 2008, p. 111). This study is important because during throttle transient, and startup conditions with port fuel injection (PFI), puddles of fuel tend to form, lengthening the time until fuel is delivered into the combustion chamber. "While much progress has been made in PFI fuel control, there are still opportunities for improvement, especially to reduce emissions during engine startup operation. As emission standards continue to tighten, optimizing engine startup has become increasingly critical" (Cowart \& Hamilton, 2008, p. 111).

Finally, in a study also reported by Cowart and Hamilton, a gasoline cooperative fuels research (CFR) engine is being used to study knock under wide-open throttle (WOT) conditions. This study is significant due to the fact that wide-open throttle operation leads to significantly hotter conditions at the intake valve during engine acceleration (Hamilton \& Cowart, 2008). These results suggest that engineers and scientists should give additional consideration to wide-open throttle operation when examining anti-knock characteristics of fuel.

\section{The Cooperative Fuels Research Engine Restoration Efforts}

Today, undergraduate students working on the fuels project are restoring and modernizing a CFR engine at Purdue University. This work is being done under the supervision of two professors, with eight undergraduate students also involved. The students are tackling the task of modernizing the engine in several ways, including updating the power generation system and the data acquisition system.

The restoration of Purdue University's CFR engine is important because this particular test engine has some capabilities shared by only a handful of CFR engines in existence, one of which is its ability to enable researchers to conduct ASTM D909 specification testing. ASTM D909 testing is critically important in the analysis of aviation gasoline, given that the D909 specification is a "laboratory test method [that] covers the quantitative determination of supercharge ratings of spark-ignition aviation gasoline" (American Society for Testing and Materials [ASTM],
2007, para. 1.1). "With regard to fuel, the FAA heavily relies on fuel specifications derived from ASTM. The FAA then certifies not the fuel but the engines and airplanes to operate on that specified fuel" (Ziulkowski, 2011, p. 121). However, it should be noted "it is necessary to run the engine under heavy detonation and at a speed not greater than $1000 \mathrm{r} / \mathrm{min}$ in order to obtain sufficient bouncing of the pin to actuate the electrical circuit and the knockmeter satisfactorily" (Royal Dutch-Shell Group, 1938, p. 242). Therefore, when utilizing this engine for ASTM D909 tests, one should not use the bouncing pin for detection of knock, as the specification requires " $1800 \pm 45 \mathrm{rpm}$, under both firing and non-firing conditions" (ASTM, 2007, para. 10.2.1). Instead, other means of knock intensity detection may be utilized.

Purdue University's CFR engine was built in 1941; therefore, the crankcase was fabricated prior to 1948 , the year in which Waukesha developed a different crankcase design. As a result, the parts for the Purdue engine have become difficult to obtain, making the restoration effort problematic. As a direct result of these challenges, students in Purdue's Aviation Technology programs are learning critical skills in project management and troubleshooting, skills which will serve the students well in their future endeavors.

\section{Conclusion}

The Cooperative Fuel Research engine is a valuable piece of testing equipment for research and development of new, unleaded aviation fuels. Attention should be given to this engine not only because of the potential educational opportunities it can provide to aviation technology students, but also because there are only a few such devices in the world that can be used to conduct ASTM D909 testing. While D909 testing is important, it is equally important to note that the engine has research applications other than the testing of substitute aviation gasolines. Such applications should prove interesting areas for further investigation in the coming years.

\section{References}

American Society for Testing and Materials (ASTM). (2007). Designation D909-07. West Conshohocken, PA: ASTM International.

Coodinating Fuel Research Committee. (1945). CFR knock-testing manual. Installation operation and maintenance for CFR testing units. New York, NY: Coordinating Research Council.

Coordinating Research Council. (2004). Handbook of aviation fuel properties. Warrendale, PA: Soceity of Automotive Engineers.

Cowart, J. S., \& Hamilton, L. J. (2008). Simultaneous in-cylinder and exhaust cycle resolved non-dispersive infrared and flame ionization detector experimental sampling results during cranking and startuup in a port fuel injection co-operatiion fuel research engine. International Journal of Engine Research, 9(2), 111-122.

Echavarria, F., Loth, J., \& Morris, G. (2006). Experiments on compression ignition by air injection(CIBAI) in a modified single-cylinder, fourstroke, spark ignition, cooperative fuel research(CFR) engine: A novel approach. SAE International. SAE Technical Paper 2006-01-3357. doi: 10.4271/2006-01-3357. 
Hamilton, L. J., \& Cowart, J. S. (2008). The first wide-open throttle engine cycle: transition into knock experiments with fast in-cylinder sampling. Internation Journal of Engine Research, 9(2), 97-109.

Kroes, M. J., \& Wild, T. W. (1995). Aircraft powerplants. Columbus, OH: Glencoe/McGraw-Hill.

National Air Transportation Association. (2011). NATA news. Retrieved from http://www.nata.aero/eNewsletters.aspx?newsid=1064\#Title3
Royal Dutch-Shell Group. (1938). A petroleum handbook. London, UK: The Asiatic Petroleum Company Limited.

United States Environmental Protection Agency. (2012b). Cars, trucks, buses, and "nonroad" equipment-plain English guide to the Clean Air Act - US EPA. Retrieved from http://www.epa.gov/air/peg/carstrucks.html

Ziulkowski, J. D. (2011). Collective knowledge on aviation gasoline. Retrieved from http://docs.lib.purdue.edu/techdirproj/43/ 